\title{
Correlation between Cognitive Aspects and Dysphagia in Patients with Amyotrophic Lateral Sclerosis: Preliminary Report
}

\author{
Maira R. Olchik¹, Marciéle Ghisi², Pablo B. Winckler ${ }^{3}$, Annelise Ayres ${ }^{4}$ \\ ${ }^{1}$ Department of Surgery and Orthopedics, Universidade Federal do Rio Grande do Sul, Porto Alegre, Brazil \\ ${ }^{2}$ Certified-SLP/Certified-A, Universidade Federal do Rio Grande do Sul, Porto Alegre, Brazil \\ ${ }^{3}$ Department of Neurology, Clinical Hospital of Porto Alegre, Porto Alegre, Brazil \\ ${ }^{4}$ Certified-SLP/Certified-A, Graduate Program in Health Sciences, Universidade Federal de Ciências da Saúde de Porto Alegre, \\ Porto Alegre, Brazil \\ Email: mairarozenfeld@hotmail.com,marieli_sa@hotmail.com,pbwinckler@hotmail.com, anneliseayres@hotmail.com
}

How to cite this paper: Olchik, M.R., Ghisi, M., Winckler, P.B. and Ayres, A. (2017) Correlation between Cognitive Aspects and Dysphagia in Patients with Amyotrophic Lateral Sclerosis: Preliminary Report. International Journal of Clinical Medicine, 8, 680-691.

https://doi.org/10.4236/ijcm.2017.812063

Received: July 12, 2017

Accepted: December 26, 2017

Published: December 29, 2017

Copyright $\odot 2017$ by authors and Scientific Research Publishing Inc. This work is licensed under the Creative Commons Attribution International License (CC BY 4.0).

http://creativecommons.org/licenses/by/4.0/

\begin{abstract}
Introduction: Cognitive impairment has been identified in 30\%-50\% of the population with Amyotrophic Lateral Sclerosis (ALS). Among these patients, dysphagia is not only a very common symptom but also one of the main bulbar symptoms. Objective: To correlate cognitive function and dysphagia in patients with ALS. Methods: a cross-sectional study. Criteria for inclusion were an ALS diagnosis and the signing of the consent form. Criteria for exclusion were patients who had undergone speech therapy, patients within sufficient oral language skills to participate in cognitive tests, patients receiving enteral feeding and patients who withdrew from the study before completing all the stages. Evaluations of cognition and dysphagia were performed. Results: The initial sample consisted of 86 participants, 69 of which fell under exclusion criteria. Seventeen patients were evaluated, with a mean age of 49.8 $( \pm 11.3)$ and a mean education period of $7.1( \pm 2.8)$ years. Disease evolution was analyzed in months, with a median of $24(\mathrm{P} 25=10 ; \mathrm{P} 75=72)$ months. In this sample, $70.6 \%$ of patients were male $(\mathrm{p}=0.019)$. Among the tests performed, those of executive functions were correlated with dysphagia: FAB ( $p$ $=0.019)$ and Trail Making Test $\mathrm{A}(\mathrm{p}=0.006)$. Conclusion: This pilot study suggests a correlation between executive functions and dysphagia.
\end{abstract}

\section{Keywords}

Cognition, Dysphagia, Amyotrophic Lateral Sclerosis

\section{Introduction}

Amyotrophic lateral sclerosis (ALS) belongs to the group of motor neuron dis- 
eases, characterized by the progressive degeneration of upper motor neurons (UMNs) and lower motor neurons (LMNs), in association with bulbar and pyramidal signs [1] [2] [3]. The involvement of these neurons results in several symptoms such as respiratory difficulties and dysphagia, as well as physical and cognitive deficits [4] [5] [6].

One of the most severe symptoms faced by patients with neurodegenerative diseases, especially those with ALS, is oropharyngeal dysphagia [6] [7]. Dysphagia is a swallowing disorder that modifies the process of transporting food safely and efficiently from mouth to pharynx to esophagus [8] [9]. Dysphagia can lead to aspiration, malnutrition, dehydration and pneumonia, all of which have a significant impact on the quality of life of patients [10] [11] [12].

Swallowing involves muscular issues as well as cognitive aspects. It is known that the anticipatory and preparatory stages of swallowing are voluntary and may be influenced by cognitive issues which, in turn, may limit self-regulation, perception and the control of risk factors, in addition to the development of compensatory strategies. Thus, in disorders such as Alzheimer's disease (AD), Parkinson's disease (PD), where cognitive functions become altered, complications related to eating and swallowing can arise [9] [10]. Although no studies specific to ALS have been found so far, this issue has already been well described in literature regarding other neurological diseases [13] [14] [15].

Although physical handicaps are most noticeable in ALS, cognitive deficits are also important. Cognitive changes can occur in 35\% - 50\% of ALS patients, which consequently lead to a spectrum of functional and behavioral deficiencies that directly influence a patient's planning and decision-making capacity. In more recent literature, ALS is recognized as a multisystemic disease that may be associated with varying degrees of cognitive and behavioral dysfunction [3] [16] [17] [18].

Although, cognition is a recently point of discussion in ALS forums, studies have shown that this clinical population may present alterations in cognitive aspects, especially executive function (EFs) alterations [19] [20] [21]. Moreover, studies have shown that individuals with ALS present cognitive impairment, regardless of the type of neuropsychological assessment performed [22] [23] [24] [25]. Understanding cognitive impairment in ALS could provide more information about the pathogenesis of neurodegeneration and inform patient care [3] [26] [27] [28].

Early screening for cognitive deficits in ALS patients may help to better direct healthcare strategies that these individuals may need during disease progression [21] [29]. It is known that, with the advancement of the disease, some phenotypes show a greater decline.

The purpose of this study is to correlate cognitive impairment and dysphagia in patients affected by ASL.

\section{Material and Methods}

\subsection{Study Design and Sample Recruitment}

This was a cross-sectional, observational and descriptive study. The sample con- 
sisted of individuals attended at a reference hospital in the city of Porto Alegre, Brazil. The research project was analyzed and approved by the Research Ethics Committee of the institution under number 150037.

The inclusion criteria were: patients with a medical diagnosis of ALS, according to the El Escorial [30] revised diagnostic criteria for definite, probable and probably laboratory-supported ALS, along with the signing of the Informed Consent form. The exclusion criteria were: patients who had previously had speech therapy for dysphagia, patients with oral language difficulties which made it impossible to perform cognitive tests, patients receiving enteral feeding and patients who dropped out before completing all the steps of the study.

Initially, a search was done to identify individuals with ALS diagnosis. In Figure 1 we present the initial sample and the final $n$ meeting the inclusion/exclusion criteria.

\subsection{Procedures}

Data collection occurred between March and October 2016. The collection was carried out in individual meetings lasting 90 minutes each. At the time of initial collection, medical and sociodemographic data were obtained. Four steps were performed: anamnesis, cognitive evaluation, questionnaires (mood and fragility) and a clinical evaluation of patient dysphagia.

To evaluate the cognitive aspects, the following instruments were used: Mini-Mental State Examination (MMSE) [31], Verbal Fluency Semantics (VFS) [32], the Categorical Verbal Fluency-Animals (VF-animal) [33], Montreal Cognitive Assessment (MoCA) [34], Frontal Assessment Battery (FAB) [35] and Trail Making Test version A and B [36]. The classification of normality was established by age and years of education, according to each cognitive test. The validated and translated versions for Brazilian Portuguese were used.

To evaluate mood we used the Beck Depression Inventory (BDI) [37] and to evaluate fragility we used the Edmonton Fragility Scale [38]. To assess patient self-perception regarding dysphagia, the Eating Assessment Tool (EAT-10) —developed by Belafsky et al. (2008) [39] and validated in Brazil by Gonçalves et

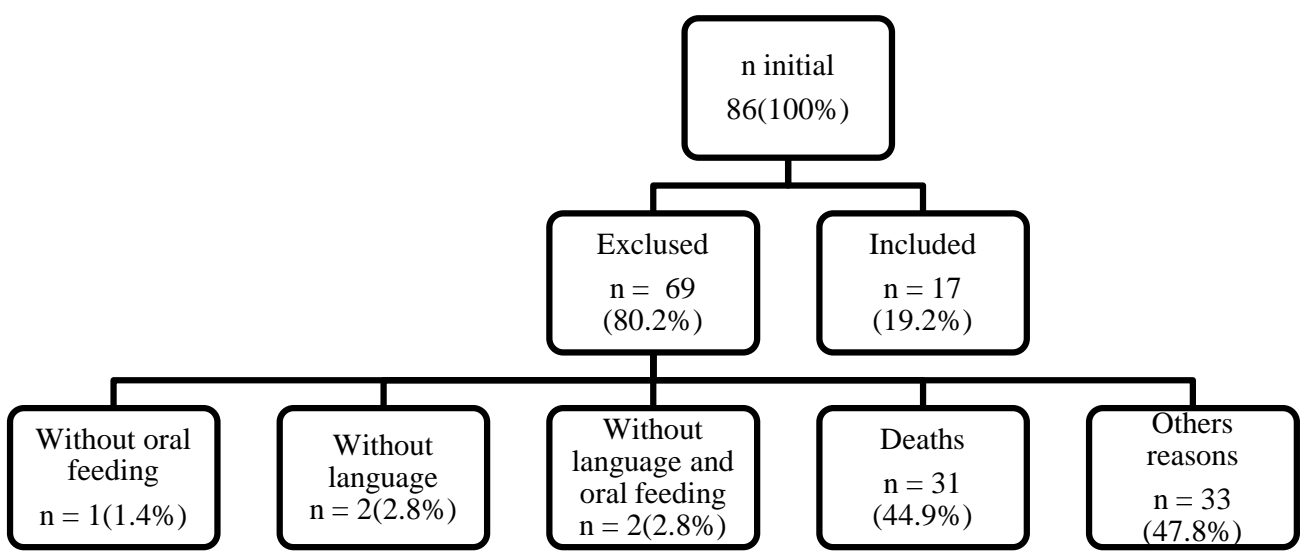

Figure 1. Sample data. 
al. (2013) [40] — was used. This test exhibited a sensitivity of $69.70 \%$ and a specificity of $72.00 \%$, parameters defined as the limit of separation between pass and fail in the feeding triage, with good accuracy. Patients who scored above three points were considered at risk for dysphagia [40].

Dysphagia was evaluated through clinical evaluation, using the Northwestern Dysphagia Patient Check Sheet-NDPCS, which was developed by Logemann et al. (1999) and validated in Brazilian Portuguese by Magalhaes (2013). This assessment was carried out with three consistencies: solid (a wafer), puree (a $50 \mathrm{~g}$ cup of yogurt) and thin liquid (a glass of $200 \mathrm{ml}$ of water). All evaluated individuals received the same type of food in the same quantity. After, each patient was classified as having or not having dysphagia, according to the signs and symptoms presented during the process. The signs and symptoms analyzed were based on those described in literature [41] [42] [43] totalizing 21 signs and symptoms which were scored as present or absent. All three types of food were offered freely without interference from the evaluator at the time of feeding.

After the evaluations, the Functional Oral Intake Scale (FOIS), developed by Crary et al. (2005), was applied. This instrument is valid and reliable and has a coefficient of reliability among evaluators of $0.98-0.99$, with mean Kappa coefficient values between 0.86 and 0.91 and adequate consensual validity (agreement of Kendall 0.90) as well as validity criteria (based on The Mann Assessment of Swallowing Ability test) [44]. The translated and validated version in Brazilian Portuguese was used [45].

\subsection{Statistical Analysis}

Quantitative variables were described by mean and standard deviation or median and interquartile range. Qualitative variables were described by absolute and relative frequencies. The t-student test was applied to compare the qualitative variables. In the case of asymmetry, the Mann-Whitney test was used. The Pearson or Spearman correlation tests were used to evaluate the association between continuous and ordinal variables respectively. The significance level adopted was $5 \%(\mathrm{p}<0.05)$ and the analyses were performed in the SPSS program version 21.0.

\section{Results}

Seventeen patients were included in this sample, with a mean age of $49.8( \pm 11.3)$ and a mean education period of $7.1( \pm 2.8)$ years. Overall disease time was analyzed in months, with a median of $24(\mathrm{P} 25=10, \mathrm{P} 75=72)$ months. In this sample, $70.6 \%$ of patients were male.

Table 1 shows the performance and classification of normal and altered individuals in cognitive assessments and questionaires.

Table 2 presents results of the clinical evaluation of dysphagia. Regarding self-perception, only 4 participants (23.4\%) scored the cutoff point for risk of dysphagia, whereas the result of the clinical evaluation showed a higher incidence of dysphagia $(n=8 ; 47.1 \%$ ). FOIS scores ranged from 5 (oral feeding with 
Table 1. Data of cognitive evaluation and questionaires.

\begin{tabular}{|c|c|}
\hline Variables & $\mathrm{n}=17$ \\
\hline MMSE - mean \pm SD & $24.9 \pm 3.6$ \\
\hline \multicolumn{2}{|l|}{ MMSE classification - n (\%) } \\
\hline Changed & $10(58.8)$ \\
\hline Normal & $7(41.2)$ \\
\hline VF-animal - mean $\pm S D$ & $13.7 \pm 4.3$ \\
\hline \multicolumn{2}{|l|}{ VF-animal classification - n(\%) } \\
\hline Changed & $2(11.8)$ \\
\hline Normal & $15(88.2)$ \\
\hline VFS - mean $\pm S D$ & $21.1 \pm 10.0$ \\
\hline \multicolumn{2}{|l|}{ VFS classification - n(\%) } \\
\hline Changed & $16(94.1)$ \\
\hline Normal & $1(5.9)$ \\
\hline $\mathrm{MoCA}-$ mean $\pm \mathrm{SD}$ & $20.4 \pm 5.3$ \\
\hline \multicolumn{2}{|l|}{ MOCA classification - n(\%) } \\
\hline Changed & $15(88.2)$ \\
\hline Normal & $2(11.8)$ \\
\hline $\mathrm{FAB}-$ mean $\pm \mathrm{SD}$ & $9.9 \pm 4.2$ \\
\hline \multicolumn{2}{|l|}{ FAB classification - n(\%) } \\
\hline Changed & $7(41.2)$ \\
\hline Normal & $10(58.8)$ \\
\hline Trail Making Test A - MD (P25 - P75) & $128(103-186)$ \\
\hline \multicolumn{2}{|l|}{ Trail Making Test A Classification - n(\%) } \\
\hline Changed & $17(100)$ \\
\hline Normal & $0(0.0)$ \\
\hline Trail Making Test B - MD (P25 - P75) & $275(132-301)$ \\
\hline \multicolumn{2}{|l|}{ Trail Making Test B Classification $-\mathrm{n}(\%)$} \\
\hline Changed & $17(100)$ \\
\hline Normal & $0(0.0)$ \\
\hline BDI- md (P25 - P75) & $9(4-14)$ \\
\hline \multicolumn{2}{|l|}{ BDI classification - $\mathrm{n}(\%)$} \\
\hline Changed & $4(23.5)$ \\
\hline Normal & $13(76.5)$ \\
\hline Fragility - FAB & $6.3 \pm 2.7$ \\
\hline \multicolumn{2}{|l|}{ Fragility classification $\mathrm{n}(\%)$} \\
\hline Changed & $11(64.7)$ \\
\hline Normal & $6(35.3)$ \\
\hline
\end{tabular}

MMSE: Mini Mental State Examination; VFS: Verbal Fluency Semantics; VF-animal: Verbal Fluency categoric-Animals; MoCA: Montreal Cognitive Assessment; FAB: Frontal Assessment Battery; BDI: Beck Depression Inventory; FRAIL: Edmonton Fragility Scale; mean \pm SD. 
various consistencies, but with special preparation or compensatory restrictions) to 7 (oral feeding without restrictions).

Table 3 shows the correlations between cognitive aspects and dysphagia. Among the tests performed, these Executive Functions (EFs) tests were correlated with dysphagia: FAB $(p=0.019)$ and Trail Making Test A $(p=0.006)$. BDI was also significant when associated with dysphagia $(p=0.015)$.

BDI also correlated with EAT-10 ( $\mathrm{rs}=0.596, \mathrm{p}=0.012)$ and FOIS ( $\mathrm{rs}=-0.610$, $\mathrm{p}=0.009)$. Fragility was associated with FOIS ( $r s=-0.592 ; \mathrm{p}=0.012)$.

Schooling correlated with the MMSE $(\mathrm{p}=0.021-\mathrm{r}=0.553)$, VF-animal $(\mathrm{p}=$ $0.036-r=0.512)$ and MoCA $(p=0.031-r=0.523)$. Disease duration presented correlation only in the Trail Making test A $(p=0.029-r=0.529)$. Age was not

Table 2. Self-perception data and clinical evaluation of dysphagia and FOIS.

\begin{tabular}{cc}
\hline Vaiables & $\mathbf{n}=17$ \\
\hline EAT-10 - md (P25 - P75) & $0(0-5)$ \\
EAT-10 classification - $\mathrm{n}(\%)$ & \\
Changed & $4(23.5)$ \\
Normal Swallowing clinical assessment $-\mathrm{n}(\%)$ & $13(76.5)$ \\
Changed & $8(47.1)$ \\
Normal & $9(52.9)$ \\
FOIS - n(\%) & $6(35.3)$ \\
5 & $3(17.6)$ \\
6 & $8(47.1)$ \\
7 &
\end{tabular}

EAT-10-Eating Assessment Tool; FOIS-Functional Oral Intake Scale.

Table 3. Association between cognitive data and clinical evaluation of dysphagia.

\begin{tabular}{cccc}
\hline Variables & With dysphagia & Without dysphagia & p \\
\hline MMSE - mean \pm SD & $24.8 \pm 2.3$ & $25.0 \pm 4.5$ & $0.890^{\mathrm{a}}$ \\
VF-animal - mean \pm SD & $12.1 \pm 3.6$ & $15.1 \pm 4.6$ & $0.157^{\mathrm{a}}$ \\
VFS - mean \pm SD & $21.5 \pm 10.5$ & $20.7 \pm 10.3$ & $0.871^{\mathrm{a}}$ \\
MoCA - mean \pm SD & $19.5 \pm 5.2$ & $21.2 \pm 5.5$ & $0.521^{\mathrm{a}}$ \\
FAB - mean \pm SD & $7.5 \pm 4.2$ & $12.1 \pm 2.9$ & $0.019^{\mathrm{a}}$ \\
Trail Making Test A - MD & $500^{* *}\left(220-500^{* *}\right)$ & $110(85.5-160)$ & $0.006^{\mathrm{b}}$ \\
$\quad($ P25 - P75) & & & \\
Trail Making Test B - MD & $500^{* *}\left(301^{*}-500^{* *}\right)$ & $275\left(132-500^{* *}\right)$ & $0.093^{\mathrm{b}}$ \\
(P25 - P75) & $13(9-23)$ & $4(4-8)$ & $0.015^{\mathrm{b}}$ \\
BDI - md (P25 - P75) & $7.63 \pm 2.9$ & $5.11 \pm 1.97$ & $0.053^{\mathrm{a}}$ \\
FRAIL - mean \pm SD &
\end{tabular}

MMSE: Mini Mental State Examination; VFS: Verbal Fluency Semantics; VF-animal: Verbal Fluency categoric-Animals; MoCA: Montreal Cognitive Assessment; FAB: Frontal Assessment Battery; BDI: Beck Depression Inventory; FRAIL: Edmonton Fragility Scale; ${ }^{*}$ Represents the patients who took more than 5 minutes to perform the test ${ }^{* *}$ represents the patients who were unable to perform the test a-Student's test $\mathrm{b}-$ Mann-Whitney test; mean $\pm \mathrm{SD}$. 
significantly associated with cognitive and swallowing data $(\mathrm{p}>0.10)$.

\section{Discussion}

According to the results, oropharyngeal dysphagia was present in $47.1 \%$ of the patients in this sample; however, regarding self-perception of dysphagia, only $23.5 \%$ of the subjects reported feeding difficulties.As we have seen in the literature, dysphagia is widely discussed in ALS forums, as it is one of the most prevalent symptoms of the disease, and it is even one of the initial bulbar symptoms [10] [46] [47] [48] [49] [50].

However, in our study, we were able to show that executive functions and dysphagia demonstrated a significant correlation, confirming the initial hypothesis of our study with this sample. It is already known that swallowing is also a planning process and therefore an action commanded by the brain. Executive functions (EFs) are always required once action planning needs to take place or when a sequence of appropriate responses needs to be defined or organized. In this way, EFs assist in the selection of the most efficient strategies in order to solve immediate, medium-term and long-term problems [51] [52].

Depressive symptoms are quite common in ALS. They may appear in the first year of diagnosis and persist during the course of the disease, often making clinical management difficult [53] [54]. Psychosocial factors frequently play a significant role in the evolution of the disease and, besides issues related to quality of life (QOL) and food, patients with depression are at higher risk of dying than non-depressives [55] [56]. In a cohort study of 81 patients with ALS [7], the degree of dysphagia was verified along with overall disease progression, both with reference to swallow-related QOL. It was observed that swallow-related QOL was moderately reduced in these patients and profoundly impacted on ALS aspirators as well as on individuals in the advanced stages of the disease. These findings corroborate our observation that depressive symptoms correlated with dysphagia in our study sample.

Unlike other variables, total disease time had little impact and correlated only with the Trail Making Test A; a finding which led us to question if motor aspects could have influenced patient performance in this test. It is necessary, therefore, for us to further discuss whether the cognitive evaluation of these patients was a sound test.

The heterogeneity of ALS presents a significant challenge for an interdisciplinary team because the disease has a progressive course and creates a demand for adequate care in order to deal with the progression of the disease and the necessary, constant changes in intervention. What is more, the fragility or incapacity of these patients could be a useful parameter in decision making, regarding treatment and intervention. In our sample, fragility was associated with the FOIS scale, showing that the greater the functional disability of these individuals, the more food modification they resort to. This is due to the inability or the decreased strength of the oropharyngeal musculature, by cause of general muscular 
degeneration [4].

\section{Study Limitations}

Because of the small sample, it is reasonable to suppose that a larger number of subjects could confer more reliability to the results. Number of participants alone, however, does not make it impossible to generalize data. As such, developing longitudinal studies is imperative to verify the influence of overall disease time on cognitive performance and swallowing.

\section{Conclusion}

In conclusion, this pilot study suggests a correlation between executive functions and dysphagia. Our findings serve to underline the importance of early dysphagia intervention in ALS patients whose altered executive functions are detected by neuropsychological tests. Further investigation correlation between mood, dysphagia and neuropsychological features is focus for future research.

\section{References}

[1] Palermo, S., Lima, J.M.B. and Alvarenga, R.B. (2009) Epidemiology of Amyotrophic Lateral Sclerosis-Europe/North America/South America/Asia. Discrepancies and similarities. Systematic Review of the Literature. Revista Brasileira de Neurologia, 45, 5-10.

[2] Lima, S.R. and Gomes, K.B. (2010) Amyotrophic Lateral Sclerosis and Stem Cells Treatment. Revista Brasileira de Clínica Médica, 8, 531-537.

[3] Murphy, J., Factor-Litvak, P., Goetz, R., Lomen-Hoerth, C., Nagy, P.L., Hupf, J. and et al. (2016) Cognitive-Behavioral Screening Reveals Prevalent Impairment in a Large Multicenter ALS Cohort. Neurology, 86, 813-820. https://doi.org/10.1212/WNL.0000000000002305

[4] Fattori, B., Siciliano, G., Mancini, V., Bastiani, L., Bongioanni, P., Caldarazzo, I.E. and et al. (2017) Dysphagia in Amyotrophic Lateral Sclerosis: Relationships between Disease Progression and Fiberoptic Endoscopic Evaluation of Swallowing. Auris Nasus Larynx, 44, 306-312. https://doi.org/10.1016/j.anl.2016.07.002

[5] Jani, M.P. and Gore, G.B. (2016) Swallowing Characteristics in Amyotrophic Lateral Sclerosis. NeuroRehabilitation, 39, 273-276. https://doi.org/10.3233/NRE-161357

[6] Erdem, N.S., Karaali, K., Ünal, A., Kızılay, F., Öğüş, C. and Uysal, H. (2016) The Interaction between Breathing and Swallowing in Amyotrophic Lateral Sclerosis. Acta Neurologica Belgica, 116, 549-556. https://doi.org/10.1007/s13760-016-0643-0

[7] Tabor, L., Gaziano, J., Watts, S., Robison, R. and Plowman, E.K. (2016) Defining Swallowing-Related Quality of Life Profiles in Individuals with Amyotrophic Lateral Sclerosis. Dysphagia, 31, 376-382. https://doi.org/10.1007/s00455-015-9686-2

[8] Logemann, J.A., Veis, S. and Colangelo, L. (1999) A Screening Procedure for Oropharyngeal Dysphagia. Dysphagia, 14, 44-51. https://doi.org/10.1007/PL00009583

[9] Logemann, J.A. (2014) Critical Factors in the Oral Control Needed for Chewing and Swallowing. Journal of Texture Studies, 45, 173-179. https://doi.org/10.1111/jtxs.12053

[10] Paris, G., Martinaud, O., Petit, A., Cuvelie, R.A., Hannequin, D., Roppeneck, P. and et al. (2013) Oropharyngeal Dysphagia in Amyotrophic Lateral Sclerosis Alters 
Quality of Life. Journal of Oral Rehabilitation, 40, 199-204.

https://doi.org/10.1111/joor.12019

[11] Ruoppolo, G., Schettino, I., Frasca, V., Giacomelli, E., Prosperini, L., Cambieri, C., and et al. (2013) Dysphagia in Amyotrophic Lateral Sclerosis: Prevalence and Clinical Findings. Acta Neurologica Scandinavica, 128, 397-401. https://doi.org/10.1111/ane.12136

[12] Simione, M., Wilson, E.M., Yunusova, Y. and Green, J.R. (2016) Validation of Clinical Observations of Mastication in Persons with ALS. Dysphagia, 31, 367-375. https://doi.org/10.1007/s00455-015-9685-3

[13] Kim, J.S., Youn, J., Suh, M.K., Kim, T.E., Chin, J., Parque, S. and Cho, J.W. (2015) Cognitive and Motor Aspects of Parkinson's Disease Associated with Dysphagia. Canadian Journal of Neurological Sciences, 42, 395-400. https://doi.org/10.1017/cjn.2015.304

[14] Kuzmickienè, J. and Kaubrys, G. (2016) Specific Features of Executive Dysfunction in Alzheimer-Type Mild Dementia Based on Computerized Cambridge Neuropsychological Test Automated Battery (Cantab) Test Results. Medical Science Monitor, 8, 22, 3605-3613. https://doi.org/10.12659/MSM.900992

[15] Braga-Neto, P., Pedroso, J.L., Alessi, H., Dutra, L.A., Felício, A.C., Minett, T., Weisman, P., Santos-Galduroz, R.F., Bertolucci, P.H., Gabbai, A.A. and Barsottini, O.G. (2012) Cerebellar Cognitive Affective Syndrome in Machado Joseph Disease: Core Clinical Features. Cerebellum, 11, 549-556. https://doi.org/10.1007/s12311-011-0318-6

[16] KhinKhin, E., Minor, D., Holloway, A. and Pelleg, A. (2015) Decisional Capacity in Amyotrophic Lateral Sclerosis. Journal of the American Academy of Psychiatry and the Law, 43, 210-217.

[17] Hsieh, et al. (2016) Cognitive and Behavioral Symptoms in ALSFTD: Detection, Differentiation, and Progression. Journal of Geriatric Psychiatry and Neurology, 29, 3-10. https://doi.org/10.1177/0891988715598232

[18] Consonni, M., Catricalà, E., Dalla, Bella, E., Gessa, V.C., Lauria, G. and Cappa, S.F. (2016) Beyond the Consensus Criteria: Multiple Cognitive Profiles in Amyotrophic Lateral Sclerosis? Cortex, 81, 162-167. https://doi.org/10.1016/j.cortex.2016.04.014

[19] Montuschi, A., Lazzolino, B., Calvo, A., Moglia, C., Lopiano, L. and Restagno, G. (2013) Cognitive Correlates in Amyotrophic Lateral Sclerosis: A Population-Based Study in Italy. Journal of Neurology, Neurosurgery, and Psychiatry, 86, 168-173. https://doi.org/10.1136/jnnp-2013-307223

[20] Papeop, L., Cecchetto, C., Mazzon, G., Granello, G., Cattaruzza, T., Verriello, L., et al. (2015) The Processing of Actions and Action-Words in Amyotrophic Lateral Sclerosis Patients. Cortex, 64, 136-147. https://doi.org/10.1016/j.cortex.2014.10.007

[21] Watermeyer, T.J., Brown, R.G., Sidle, K.C.L., Oliver, D.J., Allen, C., Karlsson, J., Ellis, K.M., Shaw, C.E., Al-Chalabi, A. and Goldstein, L.H. (2015) Executive Dysfunction Predicts social Cognition Impairment in Amyotrophic Lateral Sclerosis. Journal of Neurology, 262, 1681-1690. https://doi.org/10.1007/s00415-015-7761-0

[22] Rippon, G.A., Scarmeas, N., Gordon, P.H., Murphy, P.L., Albert, S.M. and Mitsumoto, H. (2006) An Observational Study of Cognitive Impairment in Amyotrophic Lateral Sclerosis. Archives of Neurology, 63, 345-352. https://doi.org/10.1001/archneur.63.3.345

[23] Burke, T., Pinto-Grau, M., Lonergan, K., Elamin, M., Bede, P. and Costello, E. (2016) Measurement of Social Cognition in Amyotrophic Lateral Sclerosis: A Population Based Study. PLoS ONE, 11, e0160850. 
https://doi.org/10.1371/journal.pone.0160850

[24] Prudlo, J., König, J., Schuster, C., Kasper, E., Büttner, A., Teipel, S. and Neumann, M. (2016) TDP-43 Pathology and Cognition in ALS: A Prospective Clinicopathologic Correlation Study. Neurology, 87, 1019-1023. https://doi.org/10.1212/WNL.0000000000003062

[25] Irwin, D., Lippa, C.F. and Swearer, J.M. (2007) Cognition and Amyotrophic Lateral Sclerosis (ALS). American Journal of Alzheimer's Disease \& Other Dementias, 22, 300-312. https://doi.org/10.1177/1533317507301613

[26] Branco, L.M., Zanao, T., De Rezende, T.J., Casseb, R.F., Balthazar, M.F., Woolley, S.C., et al. (2017) Transcultural Validation of the ALS-CBS Cognitive Section for the Brazilian Population. Amyotrophic Lateral Sclerosis and Frontotemporal Degeneration, 18, 60-67. https://doi.org/10.1080/21678421.2016.1211147

[27] Niven, E., Newton, J., Foley, J., Colville, S., Swingler, R., Chandran, S., et al. (2015) Validation of the Edinburgh Cognitive and Behavioural Amyotrophic Lateral Sclerosis Screen (ECAS): A Cognitive Tool for Motor Disorders. Amyotrophic Lateral Sclerosis and Frontotemporal Degeneration, 16, 172-179. https://doi.org/10.3109/21678421.2015.1030430

[28] Phukan, J., Pender, N.P. and Hardiman, O. (2007) Cognitive Impairment in Amyotrophic Lateral Sclerosis. The Lancet Neurology, 6, 994-1003. https://doi.org/10.1016/S1474-4422(07)70265-X

[29] Calvo, U., Moglia, C., Lunetta, C., Marinou, K., Ticozzi, N., Ferrante, G.D., et al. (2017) Factors Predicting Survival in ALS: A Multicenter Italian Study. Journal of Neurology, 264, 54-63. https://doi.org/10.1007/s00415-016-8313-y

[30] Brooks, B.R., Miller, R.G., Swash, M., et al. (2000) El Escorial Revisited: Revised Criteria for the Diagnosis of Amyotrophic Lateral Sclerosis. Amyotrophic Lateral Sclerosis and Frontotemporal Degeneration, 1, 293-299. https://doi.org/10.1080/146608200300079536

[31] Bertolucci, P.H.F., Brucki, S.M.D., Campacci, S.R. and Juliano, Y. (1994) The Mini-Mental State Examination in an Outpatient Population: Influence of Literacy. Arquivos de Neuro-Psiquiatria, 52, 1-7. https://doi.org/10.1590/S0004-282X1994000100001

[32] Benton, A.L. and Hamsher, K. (1989) Multilingual Aphasia Examination. AJA Associates, Iowa City.

[33] Brucki, S.M.D., Malheiros, S.M.F., Okamoto, I.H. and Bertolucci, P.H.F. (1997) Normative Data: Category Verbal Fluency. Arquivos de Neuro-Psiquiatria, 55, 56-61. https://doi.org/10.1590/S0004-282X1997000100009

[34] Sarmento, A.R.L. (2009) Presentation and Applicability of the Brazilian Version the MoCA (Montreal Cognitive Assessment) for Screening of Mild Cognitive Impairment. Dissertação, Universidade Federal de São Paulo, São Paulo.

[35] Beato, R.G., Nitrini, R., Formigoni, A.P. and Caramelli, P. (2007) Brazilian Version of the Frontal Assessment Battery (FAB): Preliminary Data on Administration to Healthy Elderly. Dementia \& Neuropsychologia, 1, 59-65. https://doi.org/10.1590/S1980-57642008DN10100010

[36] Tombaugh, T.N. (2004) Trail Making Test A and B: Normative Data Stratified by Age and Education. Archives of Clinical Neuropsychology, 19, 203-214. https://doi.org/10.1016/S0887-6177(03)00039-8

[37] Gomes-Oliveira, M.H., Gorenstein, C., Neto, F.L., Andrade, L.H. and Wang, Y.P. (2012) Validation of the Brazilian Portuguese Version of the Beck Depression In- 
ventory II in a Community Sample. Revista Brasileira De Psiquiatria, 34, 389-394. https://doi.org/10.1016/j.rbp.2012.03.005

[38] Fabricio-Wehble, S.C.C. (2008) Cross-Cultural Adaptation and Validation of the Edmontn Frail Scale (FES) Elderly Frailty Assessment Scale. PhD Dissertação, São Paulo.

[39] Belafsky, P.C., Mauadeb, D.A., Rees, C.J., Pryor, J.C., Postma, G.N., Allen, J., et al. (2008) Validity and Reliability of the Easting Assessment Tool (EAT-10). Annals of Otology, Rhinology \& Laryngology, 117, 919-924. https://doi.org/10.1177/000348940811701210

[40] Gonçalves, M.I.R., Remaili, K.B. and Behlau, M. (2013) Cross-Cultural Adaptation of the Brazilian Version of the Eating Assessment Tool EAT-10. CoDAS, 25, 601-604. https://doi.org/10.1590/S2317-17822013.05000012

[41] Logemann, J.A. and Larsen, K. (2012) Oropharyngeal Dysphagia: Pathophysiology and Diagnosis for the Anniversary Issue of Diseases of the Esophagus. Diseases of the Esophagus, 25, 299-304. https://doi.org/10.1111/j.1442-2050.2011.01210.x

[42] Magalhaes Junior, H.V., et al. (2013) Translation and Cross-Cultural Adaptation of the Northwestern Dysphagia Patient Check Sheet to Brazilian Portuguese. CoDAS, 25, 369-374. https://doi.org/10.1590/S2317-17822013000400012

[43] Padovani, A.R. (2010) Oral Feeding Transition Protocolo (OFTP) MD. Dissertação, Universidade de São Paulo, São Paulo.

[44] Crary, M.A., Mann, G.D. and Groher, M.E. (2005) Initial Psychometric Assessment of a Functional Oral Intake Scale for Dysphagia in Stroke Patients. Archives of Physical Medicine and Rehabilitation, 86, 1516-1520. https://doi.org/10.1016/j.apmr.2004.11.049

[45] Furkim, A.M. and Sacco, A.B.F. (2008) Efficacy of Speech Therapy in Neurogenic Dysphagia using Functional Oral Intake Scale (FOIS) as a Parameter. Revista CEFAC, 10, 503-512. https://doi.org/10.1590/S1516-18462008000400010

[46] Plowman, E.K., Tabor, I.C., Robison, R., Gaziano, J., Dion, C., Watts, S.A., Vu, T. and Gooch, C. (2016) Discriminant Ability of the Eating Assessment Tool-10 to Detect Aspiration in Individuals with Amyotrophic Lateral Sclerosis. Neurogastroenterology \& Motility, 28, 85-90. https://doi.org/10.1111/nmo.12700

[47] Munoro, S., et al. (2015) Evaluation of Dysphagia at the Initial Diagnosis of Amyotrophic Lateral Sclerosis. Auris Nasus Larynx, 42, 213-217. https://doi.org/10.1016/j.anl.2014.10.012

[48] Solazzo, A., Del Vecchio, L., Reginelli, A., Monaco, L., Sagnelli, A., Monsorrò, M., et al. (2011) Search for Compensation Postures with Videofluoromanometric Investigation in Dysphagic Patients Affected by Amyotrophic Lateral Sclerosis. La Radiologia Medica, 116, 1083-1094. https://doi.org/10.1007/s11547-011-0698-1

[49] Easterling, C., Antinoja, J., Cashin, S. and Barkhaus, P.E. (2013) Changes in Tongue Pressure, Pulmonary Function, and Salivary Flow in Patients with Amyotrophic Lateral Sclerosis. Dysphagia, 28, 217-225. https://doi.org/10.1007/s00455-012-9436-7

[50] Ahmed, R.M., Caga, J., Devenney, E., Hsieh, S., Bartley, L., Highton-Williamson, E., et al. (2016) Cognition and Eating Behavior in Amyotrophic Lateral Sclerosis: Effect on Survival. Journal of Neurology, 263, 1593-1603. https://doi.org/10.1007/s00415-016-8168-2

[51] Mourão-Junior, C.A. and Melo, L.B.R. (2011) Integration of Three Concepts: Executive Function, Working Memory and Learning. Psicologia: Teoria e Pesquisa, 27, 
309-314.

[52] Carluer, L., Mondou, A., Buhour, M.S., Laisney, M., Pelerin, A., Eustache, F., Viader, F. and Desgranges, B. (2015) Neural Substrate of Cognitive Theory of Mind Impairment in Amyotrophic Lateral Sclerosis. Cortex, 65, 19-30.

https://doi.org/10.1016/j.cortex.2014.12.010

[53] Van Groenestijn, A.C., Kruitwagen-Van, Reenen, E.T., Visser-Meily, J.M., Van den Berg, L.H. and Schröder, C.D. (2016) Associations between Psychological Factors and Health-Related Quality of Life and Global Quality of Life in Patients with ALS: A Systematic Review. Health and Quality of Life Outcomes, 14, 107. https://doi.org/10.1186/s12955-016-0507-6

[54] Roos, E., Mariosa, D., Ingre, C., Lundholm, C., Wirdefeldt, K., Roos, P.M. and Fang, F. (2016) Depression in Amyotrophic Lateral Sclerosis. Neurology, 86, 2271-2277. https://doi.org/10.1212/WNL.0000000000002671

[55] McDonald, E., Wiedenfeld, S.A., Hillel, A., Carpenter, C.L. and Walter, R.A. (1994) Survival in Amyotrophic Lateral Sclerosis. The Role of Psychological Factors. Archives of Neurology, 51, 17-23.

https://doi.org/10.1001/archneur.1994.00540130027010

[56] Chio, A., Logroscino, G., Hardiman, O., Swingler, R., Mitchell, D. and EttoreBeghi, E. (2009) Prognostic Factors in ALS: A Critical Review. Amyotrophic Lateral Sclerosis, 10, 310-323. https://doi.org/10.3109/17482960802566824 